\title{
YkrB is the main peptide deformylase in Bacillus subtilis, a eubacterium containing two functional peptide deformylases
}

\author{
Michael Haas, Dieter Beyer, Reinhold Gahlmann and Christoph Freiberg
}

Institute for Anti-infectives Research, Pharma Research, Bayer AG, D-42096 Wuppertal, Germany
Author for correspondence: Christoph Freiberg. Tel: +49202 368461. Fax: +49202364116. e-mail: Christoph.Freiberg.CF@bayer-ag.de

Peptide deformylation is an essential process in eubacteria. The peptide deformylase Def has been suggested to be an attractive target for antibacterial drug discovery. Some eubacteria including medically important pathogens possess two def-like genes. Until now, the functionality of both genes has been tested only in Staphylococcus aureus with the result that one gene copy was functional. Here, expression of two functional def-like gene products in Bacillus subtilis is demonstrated. Besides the def gene, which is chromosomally located close to the formyltransferase gene fmt and which was overexpressed and biochemically tested previously, B. subtilis possesses a second def-like gene, called ykrB. The encoded protein is $32 \%$ identical to the def gene product. It was shown that either def or ykrB had to be present for growth of $B$. subtilis in rich medium (each was individually dispensable). Studies with a deflykrB double deletion strain with xylose-inducible ykrB copy demonstrated that, besides def, the gene $y k r B$ is a second cellular target of deformylase inhibitors such as the antibiotic actinonin. The gene products exhibited similar enzymic properties, exemplified by similar inhibition efficacy of actinonin in biochemical assays. Antibiotic susceptibility tests with different deletion strains and Northern analyses indicated that YkrB is probably the predominant deformylase in $B$. subtilis. It was shown that duplication of the deformylase function does not lead to an increased actinonin-resistance frequency in comparison to $B$. subtilis mutants carrying only one deformylase gene.

Keywords: underexpression mutants, antibiotic resistance, formyltransferase, actinonin, antibacterial target

\section{INTRODUCTION}

In eubacteria, nascent polypeptide chains carry $\mathrm{N}$ formylmethionine as the first amino acid, and this is removed during protein maturation by the action of two enzymes: the peptide deformylase (Def) and the methionine aminopeptidase (Map) (Adams, 1968; Sherman et al., 1985). The deformylation is a requirement for the activity of Map (Solbiati et al., 1999) and probably therefore an essential process in eubacteria, as shown in Escherichia coli (Mazel et al., 1994; Meinnel \& Blanquet, 1994) and Staphylococcus aureus (Margolis et

\footnotetext{
Abbreviations: fMAS, $\mathrm{N}$-formylmethionine-alanine-serine; $\mathrm{IC}_{50}$, inhibitor concentration which inhibits $50 \%$ of enzyme activity; $K_{\mathrm{i}}$, dissociation constant; $K_{\mathrm{m}}$, Michaelis constant; MAS, methionine-alanine-serine; MLS, macrolide/lincosamide/streptogramin.
}

al., 2000). Only when the $N$-formyltransferase (Fmt), catalysing the formylation of the initiator methionyl tRNA (tRNA ${ }^{\mathrm{fMet}}$ ), is inactivated does the def gene seem to be non-essential for bacterial survival and can be deleted (Mazel et al., 1994).

Formylated proteins exist not only in eubacteria, but also in mitochondria and plastids (Kozak, 1983); various plant mitochondria and chloroplasts possess Def activity (Braun \& Schmitz, 1993; Shanklin et al., 1995) but it has not been detected in mammalian mitochondria (for a review see Giglione et al., 2000).

The def gene was first isolated from E. coli (Meinnel \& Blanquet, 1993; Mazel et al., 1994). Subsequently, several other def genes from Gram-negative and Grampositive bacteria have been characterized on the genetic and/or biochemical level (Meinnel \& Blanquet, 1994; 
Motif 1 Motif 2 Motif 3

YKRB_BACSU
DEF(inactive)_SAU
DEF_BACST
DEF_SAU
DEF_BACSU
DEF_ECOLI

\begin{tabular}{|c|c|c|}
\hline GVGLAAPQ & EGCLS & ILNG \\
\hline AAGL & EGSIT & LHI I DQMNG \\
\hline GIGLF & EGCLS & QHEIDHLNG \\
\hline GVGLAAPQ & EGCLS & QHEIDHLNG \\
\hline GVGLAAPQ & EGCLS & QHEMDHLDG \\
\hline GIGLAATO & EGCLS & QHEMDHLV \\
\hline
\end{tabular}

Fig. 1. Multiple sequence alignment of the predicted catalytic domains of peptide deformylases. Class II deformylases: YKRB_BACSU (YkrB from B. subtilis, SWISS-PROT accession no. Q45495); DEF (inactive)_SAU [inactive Def variant translated from the genomic sequence of $S$. aureus NCTC 8325 generated at the Oklahoma University (Oklahoma City, OK, USA)]; DEF_BACST (Def from B. stearothermophilus, SWISS-PROT accession no. O31410); DEF_SAU (Def from S. aureus, Genpept accession no. AAG02249). Class I deformylases: DEF_BACSU (Def from $B$. subtilis, SWISS-PROT accession no. P94462); DEF_ECOLI (Def from E. coli, SWISS-PROT accession no. P27251). Three conserved motifs defining the catalytic domain are shown. Bold amino acid residues deviate from the conserved motifs (Meinnel et al., 1997). The positions of the motifs in protein YKRB_BACSU are: motif 1, G58-Q65; motif 2, E108-S112; motif 3, Q152-G160. Along the complete amino acid sequence, YKRB_BACSU exhibits identities of $67 \%$ to DEF_BACST, $61 \%$ to DEF_SAU, $32 \%$ to DEF_BACSU, $30 \%$ to DEF (inactive)_SAU and $27 \%$ to DEF_ECOLI.

Mazel et al., 1997; Meinnel et al., 1997; Belouski et al., 1998; Evans et al., 1998; Huntington et al., 2000; Chen et al., 2000). Def homologues have been identified in all eubacteria, but not in Archaea, Saccharomyces cerevisiae and Caenorhabditis elegans. They can also be found in eukaryotic parasites such as Plasmodium falciparum and Trypanosoma spp. (Meinnel, 2000), in higher plants such as Arabidopsis thaliana (Genpept accession no. CAB87633), in Drosophila melanogaster (Genpept accession no. AAF54540), as well as in mice and humans (GenBank accession nos BE303602 and AW499510), although their exact function, especially in the fruit fly and in mammals, is unknown. In conclusion, the Def protein, which is essential for bacterial but probably not for mammalian survival, is broadly conserved among living organisms. Thus Def has been suggested to be an attractive target for antibacterial (and eventually antiparasitic) drug discovery (Giglione et al., 2000; Meinnel, 2000).

Indeed, a potent peptide deformylase inhibitor with antibacterial activity has recently been identified (Chen et al., 2000). Actinonin is active against both Grampositive and Gram-negative bacteria, indicating a high degree of similarity among eubacterial deformylases. Based on amino acid sequence similarity, peptide deformylases can be divided into two subfamilies (Giglione et al., 2000). One is represented by the E. coli enzyme and many deformylases from Gram-negative bacteria (class I) and the second by enzymes from Bacillus stearothermophilus and many Gram-positive bacteria (class II). Meinnel et al. (1997) have already reported that B. stearothermophilus and E. coli peptide deformylases share close enzymic properties in spite of little sequence homology.
Some eubacteria possess two def genes, especially Grampositive representatives. Recently, it was shown that in $S$. aureus only one of the two genes is responsible for peptide deformylation (Margolis et al., 2000). In Bacillus subtilis, a def class I gene was cloned previously and shown to encode a functional peptide deformylase (Mazel et al., 1997; Leiting et al., 1998; Durand et al., 1999; Huntington et al., 2000). On the other hand, B. subtilis contains an additional deformylase-like gene, called $y k r B$, whose product is highly similar to the class II deformylase from B. stearothermophilus (Fig. 1). We therefore investigated whether this gene is also functional in B. subtilis. Here, we present data that B. subtilis harbours two functional peptide deformylases, in contrast to all other eubacteria studied so far. This is the first time that the biochemical and physiological roles of two functional Def proteins derived from one organism are compared.

\section{METHODS}

Materials, bacterial strains, growth conditions and plasmids. Actinonin, lysozyme, xylose and fluorescamine were purchased from Sigma Aldrich; $N$-formylmethionine-alanineserine (fMAS) and methionine-alanine-serine (MAS) were obtained from Bachem; ciprofloxacin was from Bayer. All other chemicals were of the highest commercial grade.

E. coli XL-1 Blue was used for cloning, and E. coli M15 for IPTG-induced protein overexpression (see Table 1). The gene replacement experiments were performed in B. subtilis strain 168 , which we call the wild-type strain in our studies. In this work, we generated several B. subtilis deletion strains (see Table 1).

All strains were grown in LB medium (1\% Bacto Tryptone, $0.5 \%$ yeast extract, $0.5 \% \mathrm{NaCl}$ ) with the appropriate selection. For antibiotic selection, the concentrations of antibiotics were $50 \mu \mathrm{g}$ ampicillin $\mathrm{ml}^{-1}, 5 \mu \mathrm{g}$ chloramphenicol $\mathrm{ml}^{-1}, 20 \mu \mathrm{g}$ neomycin $\mathrm{ml}^{-1}, \quad 0.5 \mu \mathrm{g}$ erythromycin $\mathrm{ml}^{-1}+12.5 \mu \mathrm{g}$ lincomycin $\mathrm{ml}^{-1}$ [for selecting macrolide/lincosamide/streptogramin (MLS) resistance] and $100 \mu \mathrm{g}$ spectinomycin $\mathrm{ml}^{-1}$. Cell densities $\left(\mathrm{OD}_{600}\right)$ were recorded with the UV-vis spectrophotometer DU-64 (Beckmann).

To overexpress proteins, the vector pQE60 (Qiagen) was used. The plasmids pJH101 (Ferrari et al., 1983) and pDG1731xyl were used for gene replacement experiments. Plasmid pDG1731xyl is a derivative of pDG1731 (Guerout-Fleury et al., 1996). A 1485 bp DNA fragment containing the xyloseregulator gene $x y l R$ and the xylose-inducible promoter of gene xylA $\mathrm{P}_{\mathrm{xylA}}$ from Bacillus megaterium was amplified from plasmid pX (Kim et al., 1996) using the primers XYL1 (5'AGAGGATCCCATTTCCCCCTTTG-3') and XYL2 (5'ATCAGATCTATCAACGTGATATAGGTTTGC-3'). The PCR product's terminal Bam HI and BglII restriction sites were used to introduce it into the BamHI site of pDG1731, so that genes could be cloned into the one remaining BamHI site downstream of $\mathrm{P}_{\mathrm{xylA}}$. Plasmid pBEST501 was used to obtain the neomycin-resistance cassette by restriction digestion with the enzymes XbaI and NotI (Itaya et al., 1989). An erythromycin-resistance cassette was obtained from pDG1731 (Guerout-Fleury et al., 1996) by amplification using the primers ERM1 (5'-ATCTCTAGACCCGGGCTTGATCCATGGATTACGCG-3') with a $5^{\prime}$-terminal XbaI site and ERM2 (5'-ATCGCGGCCGCTTACTTATTAAATAATTTATAG- 
Table 1. Bacterial strains and plasmids used in this study

\begin{tabular}{|c|c|c|}
\hline Strain/plasmid & Genotype/description* & Source or reference \\
\hline \multicolumn{3}{|l|}{ Strains } \\
\hline \multicolumn{3}{|l|}{ E. coli } \\
\hline XL-1 Blue & $\begin{array}{l}\text { recA1 endA1 gyrA96 thi hsdR17 }\left(\mathrm{r}_{\mathrm{k}}^{-} \mathrm{m}_{\mathrm{k}}^{+}\right) \text {supE44 relA1 } \lambda^{-} \text {lac } \mathrm{F} \text { (proAB } \\
\left.\text { laq }{ }^{\alpha} \mathrm{Z} \Delta \mathrm{M} 15 \text { Tn10-tet }\right)\end{array}$ & Stratagene \\
\hline M15 & nal $^{\mathrm{s}}$ str $^{\mathrm{s}}$ rif lacl ara gal mtl $F^{-}$rec $^{+}$uvr $^{+}$lon $^{+}$pREP4 $\left(\mathrm{Km}^{\mathrm{R}}\right.$ laqI $\left.I^{\mathrm{q}}\right)$ & Qiagen \\
\hline \multicolumn{3}{|l|}{ B. subtilis } \\
\hline 168 & $\operatorname{trp} C 2$ & $\begin{array}{l}\text { Anagnostopoulos \& Spizizen } \\
(1961)\end{array}$ \\
\hline MHD101 & $\Delta d e f:: n m \operatorname{trp} C 2$ & This work \\
\hline MHD104 & $\Delta d e f:: n m \Delta t h r C:: x y l R-\mathrm{P}_{\mathrm{xylA}}-\operatorname{def}-\operatorname{spc} \operatorname{trp} C 2$ & This work \\
\hline MHY101 & $\Delta y k r B:: n m \operatorname{trp} C 2$ & This work \\
\hline MHY103 & $\Delta d e f:: n m \Delta y k r B:: e r m \Delta t h r C:: x y l R-\mathrm{P}_{\mathrm{xy} 1 \mathrm{~A}}-y k r B-s p c \operatorname{trp} C 2$ & This work \\
\hline \multicolumn{3}{|l|}{ Plasmids } \\
\hline pQE60 & E. coli expression vector; resistance: ampicillin & Qiagen \\
\hline pJH101 & $\begin{array}{l}\text { Vector for gene replacement in B. subtilis; resistance: ampicillin, } \\
\text { chloramphenicol, tetracycline }\end{array}$ & Ferrari et al. (1983) \\
\hline pDG1731 & $\begin{array}{l}\text { Vector for ectopic integration at the thrC locus in B. subtilis; resistance: } \\
\text { ampicillin, MLS, spectinomycin }\end{array}$ & Guerout-Fleury et al. (1996) \\
\hline $\mathrm{pX}$ & $\begin{array}{l}\text { Vector containing } x y l R-\mathrm{P}_{\mathrm{xylA}} \text { from } B . \text { megaterium; resistance: } \\
\text { chloramphenicol, ampicillin }\end{array}$ & Kim et al. (1996) \\
\hline pDG1731xyl & $\begin{array}{l}\text { Vector containing } x y l R-\mathrm{P}_{\mathrm{xylA}} \text { from } B . \text { megaterium for ectopic integration at } \\
\text { the } t h r C \text { locus in } B . \text { subtilis; resistance: ampicillin, MLS, spectinomycin }\end{array}$ & This work \\
\hline pBEST501 & $\begin{array}{l}\text { Vector carrying a neomycin-resistance cassette; resistance: ampicillin, } \\
\text { neomycin }\end{array}$ & Itaya et al. (1989) \\
\hline
\end{tabular}

* nm, the neomycin-resistance gene; erm, the erythromycin-resistance gene; and $s p c$, the spectinomycin-resistance gene.

CTATTG-3') with a 5'-terminal NotI site, which could be digested with the respective restriction enzymes. A summary of the plasmids used in this study is given in Table 1.

E. coli and B. subtilis genetics, and PCR protocols. DNA purification, restriction digestion, ligation and transformation of E. coli were performed according to standard protocols (Sambrook et al., 1989). Genetic techniques with B. subtilis, including transformation procedures, were performed as described by Harwood \& Cutting (1990).

All PCR primers had a calculated melting temperature of approximately $60^{\circ} \mathrm{C}$. For cloning purposes, Pwo DNA polymerase (Roche) was used, and for colony PCR procedures, a mixture of Taq DNA polymerase (Roche) and Thermo Sequenase (Amersham) was used. Flanking regions and genes for cloning into expression vectors were amplified from $100 \mathrm{ng}$ B. subtilis chromosomal DNA at primer concentrations of $1 \mu \mathrm{M}$ and dNTP concentrations of $250 \mu \mathrm{M}$. Twenty-five reaction cycles of $30 \mathrm{~s}$ at $94^{\circ} \mathrm{C} / 30 \mathrm{~s}$ at $52^{\circ} \mathrm{C} / 1-2$ min at $72{ }^{\circ} \mathrm{C}$ were carried out followed by a final $5 \mathrm{~min}$ incubation at $72{ }^{\circ} \mathrm{C}$. Complementary $5^{\prime}$ - and $3^{\prime}$-flanking regions of PCR products were assembled by mixing $1 \mu \mathrm{l}$ of each PCR reaction as template for the second PCR with outward primers and under the same conditions as described before. Diagnostic PCR on bacterial colonies was performed as follows. Cell material was suspended in $50 \mu \mathrm{l} \mathrm{H}_{2} \mathrm{O}$. A PCR reaction was performed in $50 \mu \mathrm{l}$ with $5 \mu \mathrm{l}$ of the suspended colony and under the same conditions described above.

Deletion experiments in $\boldsymbol{B}$. subtilis. Deletions of the def and $y k r B$ wild-type loci were generated as follows. The $600 \mathrm{bp}$ regions upstream and downstream of the genes of interest were PCR-amplified using the following oligonucleotide combinations: DEF1A (5'-ATCGGATCCGCTGTTAACGCAAGTCAGCG-3')/DEF1B (5' -TGCGGCCGCTAAATCTAGACTCCGCAGGATGTGTGACGAC-3') and YKRB1A(5'-ATCGGATCCTAGCGTCTTTCACGTTAAATCC$\left.3^{\prime}\right)$ /YKRB1B (5'-TGCGGCCGCTAAATCTAGACTCGATGTTTTCCATAGTAATCAAG-3') for amplification of the upstream regions, including $115^{\prime}$-codons of def and seven $5^{\prime}$ codons of $y k r B$, respectively, as well as DEF2A (5'-AGTCTAGATTTAGCGGCCGCAATCTAAAATAAGTAAATACTATACAG-3')/DEF2B (5'-ATCGGATCCAATTTTTCTACCATATACATAATGG-3') and YKRB2A (5'-AGTCTAGATTTAGCGGCCGCATATTGTGTTTCCTTTCAAAGAACC-3')/YKRB2B (5'-ATCGGATCCGTTCTCGAGGGAATCGGCAG-3') for amplification of the downstream regions, including seven $33^{\prime}$-codons of def and $173^{\prime}$-codons of $y k r B$, respectively. The primers were designed such that the ends of the PCR products facing the $5^{\prime}$ - and $3^{\prime}$-regions of the genes carried a complementary tag sequence (5'-AGTCTAGATTTAGCGGCCGCA-3'). This tag sequence was used to assemble the products in a second PCR reaction using the outward primers. The outward primers contained terminal BamHI restriction sites allowing cloning of the fusion-PCR product into the Bam HI site of pJH101. The sequence cloned into pJH101 internally contained the tag sequence, which could be cut by XbaI and NotI. Using these restriction enzymes, a neomycin-resistance $\left(\mathrm{Nm}^{\mathrm{R}}\right)$ cassette derived from pBEST501 and an erythromycin-resistance cassette $\left(\mathrm{Em}^{\mathrm{R}}\right)$ derived from pDG1731 could be integrated, respectively. The resistance cassettes did not include any transcription term- 
ination sequences and were cloned in the same transcriptional orientation as the deleted genes.

The resulting pJH101 derivatives were transformed into $B$. subtilis 168 . The transformants were tested for neomycin or erythromycin resistance and chloramphenicol sensitivity in order to find clones where the deletion marker was introduced into the chromosome by a double homologous recombination event. The clones' correct genotypes were determined according to the sizes of the PCR products obtained from colony PCRs with appropriate primers flanking the regions of recombination. Correct recombinant clones were tested for their growth rate in LB medium.

Ectopic expression of the gene $y k r B$ under the control of the xylose-inducible promoter $\mathrm{P}_{\mathrm{xyla}}$ was achieved by subcloning the PCR product containing the $B$. subtilis gene into the expression vector $\mathrm{pDG} 1731 \mathrm{xyl}$ [PCR primer pair: YKRBR $\left(5^{\prime}-\right.$ ATCGGATCCATGATTACTATGGAAAACATCGTAC$\left.3^{\prime}\right) / Y_{K R B T}$ (5'-ATCGGATCCTTAGCGCTCAATTGCGATTGC-3')] and subsequent integration at the $t h r C$ locus of the $B$. subtilis def-deletion mutant by marker exchange as described elsewhere (Guerout-Fleury et al., 1996). The chromosomal integration obtained with pDG1731xyl was marked with the spectinomycin-resistance $\left(\mathrm{Spc}^{\mathrm{R}}\right)$ determinant. After ectopic integration of $y k r B$ under the control of $\mathrm{P}_{\mathrm{xyl}}$, the $B$. subtilis def-deletion mutant was transformed with a pJH101 derivative in order to delete the $y k r B$ wild-type locus. This time the transformants were selected on selective media containing $0 \cdot 25 \%(\mathrm{w} / \mathrm{v})$ xylose. Clones resistant to spectinomycin (marker of xylose-inducible $y k r B$ copy) and erythromycin (marker for the $y k r B$ wild-type locus deletion), but sensitive to MLS and chloramphenicol (markers for the presence of pDG1731 and pJH101 sequences), were selected. The clones' correct genotypes were again verified using diagnostic colony PCRs with appropriate primers. A correct recombinant clone was tested for its ability to grow on LB medium without xylose.

Ectopic expression of the gene def under the control of the xylose-inducible promoter $\mathrm{P}_{\mathrm{xylA}}$ was achieved by subcloning the PCR product containing the gene into the expression vector pDG1731xyl [PCR primer pair: DEFR (5'-ATCGGATCCATGGCAGTAAAAAAGGTCGTCAC-3')/DEFT (5'-ATCGGATCCTCATCCTTCCATATCCGCTAG-3') ] and subsequent integration at the $\operatorname{thr} C$ locus of the B. subtilis def-deletion mutant by marker exchange as described before. The strain obtained served as control for detection of high expression of def in Northern analyses.

RNA preparation and Northern analyses. Total RNA was isolated from B. subtilis with the 'Qiagen RNeasy Mini kit'. Cells were grown in $10 \mathrm{ml} \mathrm{LB}$ medium at $37^{\circ} \mathrm{C}$ until they reached $\mathrm{OD}_{600} 0 \cdot 5$. An equal volume of ice-cold killing buffer (5 $\mathrm{mM} \mathrm{MgCl}_{2} ; 20 \mathrm{mM} \mathrm{NaN}_{3} ; 20 \mathrm{mM}$ Tris/HCl, pH 7.5) was added. The cells were harvested and resuspended in $1 \mathrm{ml}$ lysis buffer $\left(25 \%, \mathrm{w} / \mathrm{v}\right.$, saccharose; $1 \mathrm{mg}$ lysozyme $\mathrm{ml}^{-1} ; 250 \mu \mathrm{M}$ EDTA; $20 \mathrm{mM}$ Tris $/ \mathrm{HCl}, \mathrm{pH} 8 \cdot 0)$. After incubation on ice for $10 \mathrm{~min}$ and centrifugation at $4000 \mathrm{~g}$ at $4{ }^{\circ} \mathrm{C}$ for $5 \mathrm{~min}$, the pellet was resuspended in $100 \mu \mathrm{l}$ TE buffer $(1 \mathrm{mM}$ EDTA; $10 \mathrm{mM}$ Tris/ $\mathrm{HCl}, \mathrm{pH} 8 \cdot 0$ ). The following isolation steps were performed according to the manufacturer's instructions. The obtained RNA $(100 \mu \mathrm{g})$ was dissolved in $\mathrm{H}_{2} \mathrm{O}$ and stored at $-80{ }^{\circ} \mathrm{C}$

Digoxigenin-labelled RNA probes were produced by run-off transcription with $1 \mu \mathrm{g}$ PCR product as template using the 'DIG RNA labelling kit' with digoxigenin-labelled UTP according to the manufacturer's instructions (Roche). The PCR product representing gene def was generated with primers DEFR (see above) and DEFTT7 (5'-CTAATACGACTCACTATAGGGAGACATCCTTCCATATCCGCTAG- $\left.3^{\prime}\right)$; the product representing $y k r B$ was obtained with primers YKRBR (see above) and YKRBTT7 (5'-CTAATACGACTCACTATAGGGAGAGCGCTCAATTGCGATTGC-3'). The $5^{\prime}$-ends of the $3^{\prime}$-terminal primers contained the promoter of the T7 RNA polymerase (see letters in italics within the primer sequences mentioned before).

Total RNA $(10 \mu \mathrm{g})$ was electrophoresed through formaldehyde gels (Sambrook et al., 1989). The RNA size standard was obtained from Gibco-BRL. After electrophoresis, RNA was transferred to a GeneScreen Plus nylon membrane (NEN) by capillary transfer using $20 \times \operatorname{SSC}(3 \mathrm{M} \mathrm{NaCl}, 0 \cdot 3 \mathrm{M}$ sodium citrate). RNA was then stained with $0 \cdot 1 \%$ methylene blue. Hybridization and subsequent detection of the RNA probe with CDP-Star as substrate were performed according to "The Dig System User's Guide for Filter Hybridization' (Roche). Briefly, the overnight hybridization with 300 ng labelled probe $\mathrm{ml}^{-1}$ as well as the four $15 \mathrm{~min}$ washing steps (twice in $2 \times$ SSC, $0 \cdot 1 \%$ SDS and twice in $0 \cdot 1 \times$ SSC, $0 \cdot 1 \%$ SDS) were carried out at $60{ }^{\circ} \mathrm{C}$. The chemiluminescence signals on the membrane were measured in the Lumi Imager F1 (Roche).

Antibiotic susceptibility tests. Microdilution MICs were determined against B. subtilis strains in 96-well microtitre plates in LB medium containing serial dilutions (twofold) of antibiotics. A starting inoculum of $0.5-1 \cdot 0 \times 10^{5}$ c.f.u. $\mathrm{ml}^{-1}$ derived from exponentially growing cells was used. The MIC was the lowest concentration of drug that yielded no visible growth after incubation for $18-24 \mathrm{~h}$ at $37^{\circ} \mathrm{C}$. End points were determined by measuring the $\mathrm{OD}_{600}$ with the microtitre plate reader EL312e (Bio-Tec Instruments).

Growth curves of $B$. subtilis strains with actinonin treatment were obtained as follows. An overnight culture of B. subtilis was diluted 100-fold into fresh LB medium and grown to $\mathrm{OD}_{600} 0 \cdot 1$. The cell cultures were diluted by 10 -fold into $50 \mathrm{ml}$ fresh $\mathrm{LB}$ medium and incubated at $37^{\circ} \mathrm{C}$. At $\mathrm{OD}_{600} 0 \cdot 4\left(10^{8}\right.$ c.f.u. $\mathrm{ml}^{-1}$ ), actinonin was added to the culture (final concentration $20 \mu \mathrm{g} \mathrm{ml}^{-1}$ ) and growth of the B. subtilis strains was continuously monitored spectrophotometrically.

Isolation of actinonin-resistant mutants. Spontaneous actinonin-resistant mutants were isolated by plating approximately $10^{8}$ c.f.u. from exponentially growing cells of $B$. subtilis on LB agar plates containing $32 \mu \mathrm{g}$ actinonin $\mathrm{ml}^{-1}$. The plates were incubated at $37^{\circ} \mathrm{C}$ overnight. Colonies that grew were transferred to $5 \mathrm{ml}$ actinonin-free LB medium and grown overnight before again determining the MICs of actinonin for such clones. Using this isolation procedure, the frequency of actinonin-resistant clones was determined.

Cloning, expression and purification of Def and YkrB. The $B$. subtilis genes def and $y k r B$ were PCR-amplified from genomic DNA of B. subtilis 168 and cloned into expression vector pQE60 (Qiagen) using NcoI and BamHI restriction sites. The oligonucleotide combinations were as follows: DEF1 $\left(5^{\prime}-\right.$ GCGCCCATGGCAGTAAAAAAGGTCGTCAC-3')/DEF2 (5'-GCGCAGATCTTCCTTCCATATCCGCTAG-3') and YKRB1 (5'-GCGCCCATGGTTACTATGGAAAACATCGTACG-3')/YKRB2 (5'-GCGCAGATCTGCGCTCAATTGCGATTGCATT-3'). The resulting plasmid constructs were confirmed by DNA sequence analysis and used to transform $E$. coli M15. The M15 strains containing the expression vectors were grown exponentially up to $\mathrm{OD}_{600} 0.5$ at $37^{\circ} \mathrm{C}$ in LBampicillin-kanamycin medium and then induced with $1 \mathrm{mM}$ IPTG for $4 \mathrm{~h}$ before harvesting by centrifugation. The proteins were purified in a single step and under native conditions using nickel-nitrilotriacetic acid columns according to the manu- 
facturer's instructions (Qiagen; QIAexpressionist manual). Subsequently, nickel sulfate was added to a final concentration of $10 \mathrm{mM}$. Proteins were quantified using BSA as standard (Bradford, 1976). The purified proteins, which were $>95 \%$ pure as estimated by SDS-PAGE, were directly tested in enzymic assays.

Enzyme assay. The deformylase activity was measured in 384well microtitre plates. Twenty microlitres of buffer $150 \mathrm{mM}$ HEPES, pH 7.0; $10 \mathrm{mM} \mathrm{NaCl} ; 0.1 \%$ Triton X-100) was mixed with $20 \mu \mathrm{l}$ enzyme solution (end concentration in $60 \mu \mathrm{l}$ assay volume: $450 \mathrm{nM}$ ) and incubated for $20 \mathrm{~min}$ at room temperature (RT). The reaction was started by addition of appropriate amounts of substrate (fMAS) and incubated for $60 \mathrm{~min}$ at RT. The free amino-terminus of the deformylated product MAS was measured by addition of $20 \mu$ l fluorescamine solution $\left(2.5 \mu \mathrm{g} \mathrm{ml}^{-1} \quad 100 \%\right.$ DMSO). Fluorescence was measured using Spectrafluor Plus (Tecan) with the excitation wavelength at $390 \mathrm{~nm}$ and the emission wavelength at $465 \mathrm{~nm}$. To determine product concentrations, standard curves were established by measuring defined concentrations of MAS mixed with fluorescamine solution spectrophotometrically.

\section{RESULTS AND DISCUSSION}

\section{$B$. subtilis contains two def-like genes and one of these has to be present for growth to occur}

B. subtilis possesses two def-like genes, def and $y k r B$. We successfully deleted each gene by replacement with neomycin cassettes engineered to enable non-polar insertions. The def-deletion mutant MHD101 as well as the $y k r B$-deletion mutant MHY101 exhibited growth rates in LB medium identical to that of wild-type $B$. subtilis (Fig. 2). Obviously, both genes were each individually non-essential for growth. Subsequently, we

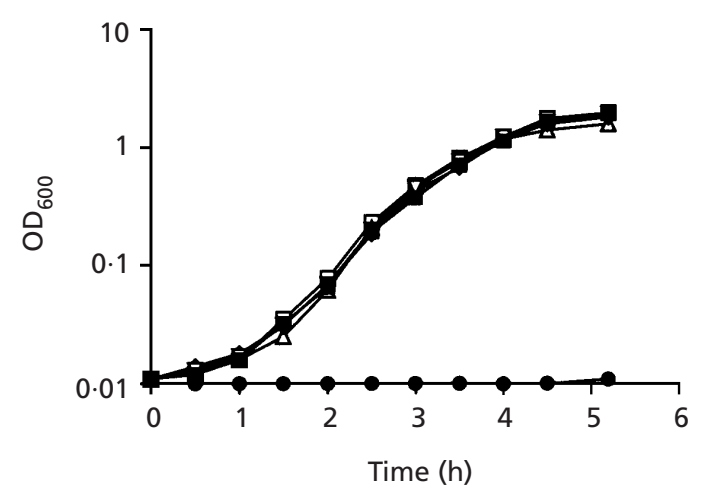

Fig. 2. Growth of $B$. subtilis mutants in LB medium. Growth of the following strains was monitored: $B$. subtilis wild-type (wt), the def-deletion strain MHD101, the $y k r B$-deletion strain MHY101, and the deflykrB double deletion strain MHY103 with xylose-inducible $y k r B$ copy. The wild-type strain and the mutant MHY103 were also grown in the presence of xylose. The experiment was performed as follows. A volume of $5 \mathrm{ml}$ xylosefree LB medium was inoculated with fresh colonies, grown on LB-agar plates with $0.25 \%$ xylose, and incubated overnight at $37^{\circ} \mathrm{C}$. Flasks containing $50 \mathrm{ml}$ LB with and without $0.25 \%(\mathrm{w} / \mathrm{v})$ xylose were inoculated with diluted aliquots of the overnight culture (start $\mathrm{OD}_{600} 0.01$ ) and incubated at $37^{\circ} \mathrm{C}$. Growth was monitored by optical density measurements. MHY103 (LB); 口, MHY103 (LB + xylose); $\nabla$, MHD101 (LB); $\diamond$, MHY101 (LB); $\triangle$, wt (LB); $\square$, wt (LB + xylose). tried to generate a mutant carrying deletions in $\operatorname{def}$ as well as in $y k r B$. We tried to replace the respective second def-like gene with an erythromycin-resistance cassette in both deletion strains MHD101 and MHY101. We were not able to generate such double deletions.

After integration of $y k r B$ downstream from a xyloseinducible promoter into the $t h r C$ region of the defdeletion strain MHD101, we were able to delete the $y k r B$ wild-type locus. The generated mutant MHY103, which carried deletions in the natural loci of def and $y k r B$ and harboured the xylose-inducible $y k r B$ copy, grew with xylose such as the $B$. subtilis wild-type, but exhibited a growth arrest over $5 \mathrm{~h}$ in xylose-free LB medium under the conditions described in Fig. 2. Afterwards, we could recover growth of strain MHY103 and harvest cells for RNA preparation $\left(\mathrm{OD}_{600} 0.5\right.$ reached after $10 \mathrm{~h}$ ), because the xylose-promoter system is leaky (Rygus \& Hillen, 1992). We demonstrated that $y k r B$ transcripts could not be detected in Northern analyses using digoxigenin-labelled probes (see Methods). In contrast, in the presence of $0.25 \%$ xylose a high amount of $y k r B$ transcripts was found in strain MHY103 (Fig. 3). We can conclude that the function encoded by def and $y k r B$, which complement each other, is essential for survival of B. subtilis.

\section{Both proteins Def and YkrB catalyse peptide deformylation}

The genes def and $y k r B$ were PCR-amplified from genomic DNA of $B$. subtilis and cloned into the expression vector pQE60. They were overexpressed in E. coli M15 and purified as proteins with C-terminal $\mathrm{His}_{6}$-tags. The proteins were tested for their peptide deformylase activity (see Methods). In order to keep the activity of the proteins stable, we saturated the enzymes with $\mathrm{NiSO}_{4}$ (Giglione et al., 2000). This treatment did not significantly change the enzymic properties of the originally purified proteins as we have tested this previously (data not shown). We could show that both proteins (Def and $\mathrm{YkrB}$ ) catalyse the deformylation of fMAS, the substrate which we used in our enzymic deformylase assay (Fig. 4). The enzymes Def and YkrB exhibited similar apparent Michaelis constants $\left(K_{\mathrm{m}}\right)$ for fMAS of $2.3 \mathrm{mM}$ and $3.0 \mathrm{mM}$, respectively. Under conditions fully saturated with substrate, $\mathrm{YkrB}$ was $2 \cdot 5$ times faster than Def (apparent turnover number $=$ $0 \cdot 17 \mathrm{~s}^{-1}$ and $0.07 \mathrm{~s}^{-1}$, respectively). Besides similar $K_{\mathrm{m}}$ values, the similarity in enzymic properties could also be demonstrated by the inhibition of their activities in the presence of actinonin. Under the same assay conditions, the actinonin concentrations which could inhibit $50 \%$ of enzyme activity $\left(\mathrm{IC}_{50}\right)$ were $95 \mathrm{nM}$ in the case of Def and $130 \mathrm{nM}$ in the case of $\mathrm{YkrB}$ (Fig. 4).

\section{Def and YkrB possess similar enzymic properties in cellular as well as cell-free systems}

Chen et al. (2000) have already demonstrated that the expression level of a deformylase in E. coli can be correlated with the antibacterial activity of actinonin, 
(a)

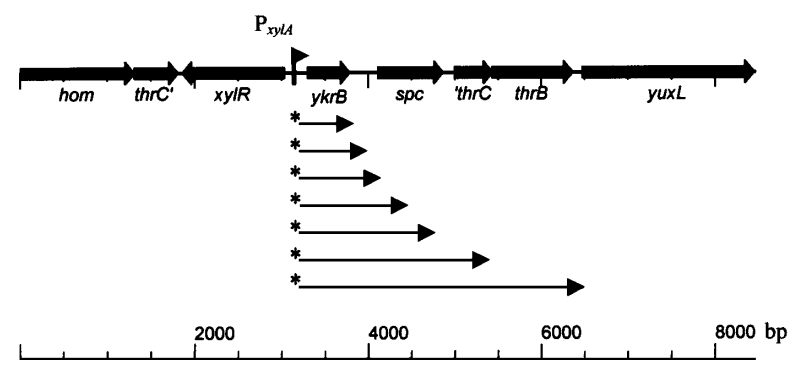

(b)

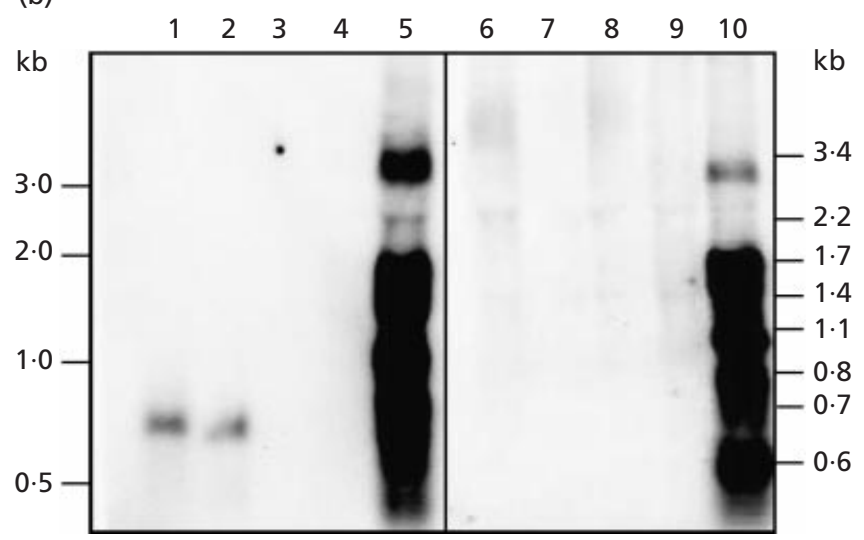

Fig. 3. (a) Gene structure of the chromosomal thrC region with integrated xylose-inducible copy of $y k r B$ such as in $B$. subtilis strain MHY103. Genes are represented by bold arrows showing the direction of transcription. Gene names are given directly below the gene map. An internal fragment of thrC is replaced by the xylose regulator gene $x y / R$, the gene $y k r B$ located downstream from the xylose-inducible promoter $\mathrm{P}_{\mathrm{xyl} I \mathrm{~A}}$, and the spectinomycin-resistance gene $s p c$. There is no strong terminator located downstream of $y k r B$. After xylose induction, $y k r B$-containing transcripts with different lengths can be detected in Northern analyses [see (b), lane 5]. The detected transcript lengths are represented by thin arrows (marked with an asterisk) and correlated with the gene map. The base pair positions in the thrC region are given underneath. (b) Northern hybridization of RNA isolated from the following $B$. subtilis strains grown in LB medium: wildtype strain (lanes 1 and 6); def-deletion strain MHD101 (lanes 2 and 7); ykrB-deletion strain MHY101 (lanes 3 and 8); deflykrB double deletion strain MHY103 with ectopic, xylose-inducible copy of $y k r B$ grown in the absence (lane 4) and presence $(0.25 \%, \mathrm{w} / \mathrm{v}$; lane 5) of xylose; def-deletion strain MHD104 with ectopic, xylose-inducible copy of def (see Table 1) grown in the absence (lane 9) and presence $(0.25 \%, w / v$; lane 10) of xylose. A digoxigenin-labelled RNA complementary to $y k r B$ was used as hybridization probe from lanes 1 to 5 , and a digoxigenin-labelled RNA complementary to def was used as hybridization probe from lanes 6 to 10. Lengths of the RNA size standard are given on the left side; transcript lengths detected with the hybridization probes are shown on the right side. While a $y k r B$ transcript could be detected [length approx. $0.7 \mathrm{~kb}$, lanes 1 and 2], no clear hybridization signal could be obtained using the def-antisense probe. Ectopic overexpression of $y \mathrm{krB}$ and def after xylose induction could be monitored (lanes 5 and 10). The def- and $y k r B$-containing transcripts have comparable sizes, because the def gene is only $70 \mathrm{nt}$ shorter than $y k r B$. The transcripts probably contain only $y k r B$ or def (approx. 0.6 and $0.8 \mathrm{~kb}$ ); $y k r B$ or def and parts of $s p c$ (approx. 1.1 and $1.4 \mathrm{~kb}$ ); $y \mathrm{krB}$ or def and complete spc (approx. $1.7 \mathrm{~kb}$ ); $y \mathrm{krB}$ or def, spc and thrC-3'-end (approx. $2.2 \mathrm{~kb}$ ); $y k r B$ or def, $s p c$, thrC-3'-end and thrB [approx. $3.4 \mathrm{~kb}$; see also part (a)].

(a)

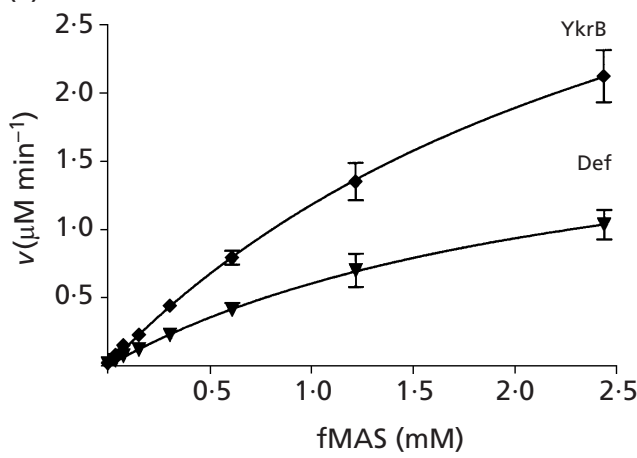

(b)

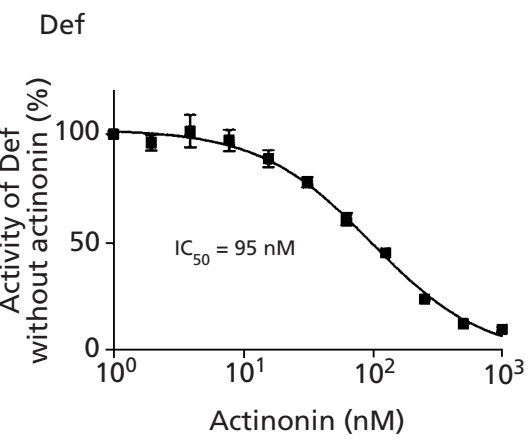

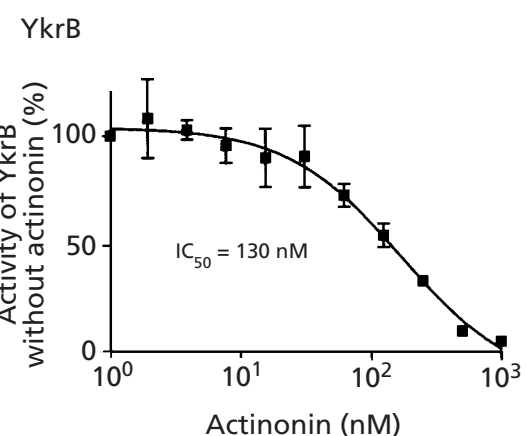

Fig. 4. Enzymic measurements with C-terminal $\mathrm{His}_{6}$-tagged $\mathrm{YkrB}$ and Def saturated with Ni. (a) Enzymic activity plotted with increasing concentrations of substrate fMAS. The curves are the best fit of the data to the Michaelis-Menten equation. The apparent $K_{\mathrm{m}}$ values are $2.3 \mathrm{mM}$ in the case of Def and $3.0 \mathrm{mM}$ in the case of YkrB. The apparent $V_{\max }$ values are $2.0 \mu \mathrm{M}$ min $^{-1}$ in the case of Def (enzyme concentration $=0.45 \mu \mathrm{M}$; deduced turnover number $=0.07 \mathrm{~s}^{-1}$ ) and $4.6 \mu \mathrm{M} \mathrm{min}{ }^{-1}$ in the case of $\mathrm{YkrB}$ (enzyme concentration $=0.45 \mu \mathrm{M}$; deduced turnover number $=0.17 \mathrm{~s}^{-1}$ ). Error bars represent the standard deviation of data reproduced four times. (b) Dose-response relationship of actinonin inhibition against Def and YkrB. Deformylation activities of $450 \mathrm{nM}$ enzymes were measured in the presence of $1.22 \mathrm{mM}$ fMAS and increasing concentrations of actinonin. The deduced $\mathrm{IC}_{50}$ values for Def and $\mathrm{YkrB}$ are given in the figure. Error bars represent the standard deviation of triplicate data. 
(a)

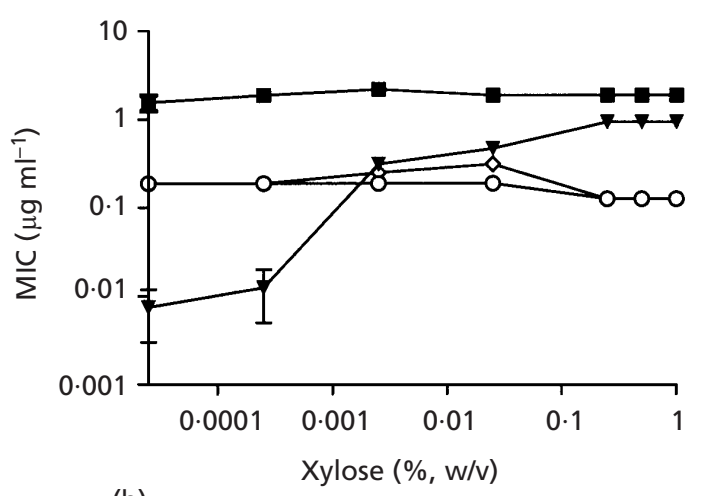

(b)

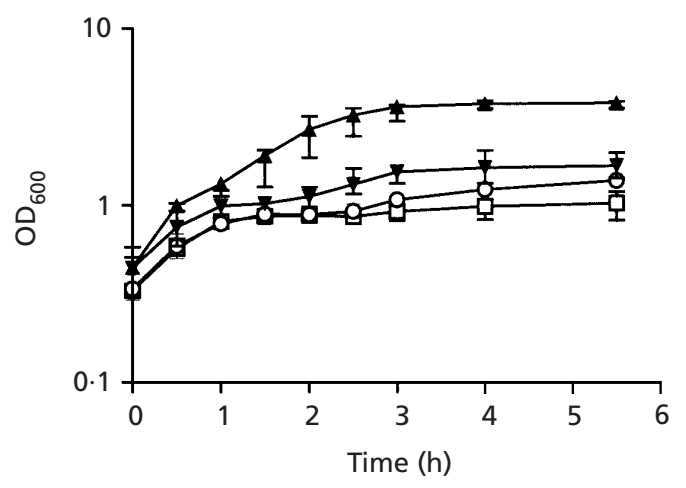

Fig. 5. Antibiotic susceptibility tests. (a) Microdilution MICs of actinonin in LB medium with different concentrations of xylose for the $B$. subtilis wild-type strain and the $\operatorname{def} / y k r B$ double deletion strain MHY103 with xylose-inducible $y k r B$ copy (see Methods). At low xylose concentrations, the actinonin MIC for strain MHY103 was $0.003-0.012 \mu \mathrm{g} \mathrm{ml}^{-1}$, while the MIC of $0.9 \mu \mathrm{g} \mathrm{ml}^{-1}$ at high xylose concentrations ( $>0.25 \%$ ) was only one dilution step $(1: 2)$ lower than the MIC for the wild-type strain $\left(1.9 \mu \mathrm{g} \mathrm{ml}^{-1}\right)$. For comparison, the MIC values of ciprofloxacin were determined. Bars indicate the minimal and maximal MIC value determined for a given condition if there were differences among three experiments performed. $\boldsymbol{\square}$, Wild-type +actinonin; $\boldsymbol{\nabla}, \mathrm{MHY} 103+$ actinonin; $\bigcirc$, wildtype + ciprofloxacin; $\diamond$, MHY103 + ciprofloxacin. (b) Growth curves of $B$. subtilis strains in LB medium with and without actinonin. After addition of $20 \mu \mathrm{g}$ actinonin $\mathrm{ml}^{-1}$ at $\mathrm{OD}_{600} 0.4$ (see Methods), growth of the following strains was monitored: $B$. subtilis wild-type strain, the def-deletion strain MHD101 and the $y k r B$-deletion strain MHY101. For comparison, growth of the strains without actinonin is shown (represented by one single curve). The mean $\mathrm{OD}_{600}$ values are given with bars representing the minimum and maximum $\mathrm{OD}_{600}$ obtained in three independent experiments. The microdilution MICs of actinonin in LB medium are $1.9 \mu \mathrm{g} \mathrm{m}^{-1}$ for $B$. subtilis wild-type and strain MHD101, and 0.3-0.5 $\mathrm{g} \mathrm{ml}^{-1}$ for strain MHY101. $\boldsymbol{\Delta}$, Strains-actinonin; $\boldsymbol{\nabla}$, wild-type+actinonin; $O$, MHD101+ actinonin; $\square$, MHY101+actinonin.

the most potent deformylase inhibitor known so far. We repeated this experiment in B. subtilis with the $\operatorname{def} / y k r B$ double deletion mutant MHY103, in order to confirm that $\mathrm{YkrB}$ is also a deformylase targeted by actinonin inside the cell. We determined the dependence of the MIC values for the mutant on different xylose concentrations, the inductor for $y k r B$ expression. We obtained no correlation between the MIC values of the control compound ciprofloxacin, which does not inhibit deformylase activity, and the xylose concentration. However, a strong correlation was observed between MIC values of actinonin and the xylose concentration, showing that $\mathrm{YkrB}$ is indeed targeted by actinonin in the cellular system (Fig. 5a).

At high xylose concentrations $(>0 \cdot 25 \%)$ no further increase in MIC values could be detected (Fig. 5a). Similar results were reported by Chen et al. (2000), who used an E. coli strain with an arabinose-inducible def gene. This plateau in MIC values might indicate that at high inductor concentrations the deformylase activity of the induced protein is no longer proportional to the inductor concentration.

The B. subtilis peptide deformylase Def has already been successfully isolated and tested for deformylase function (Leiting et al., 1998; Durand et al., 1999; Huntington et al., 2000). Peptide thiol-like deformylase inhibitors exhibiting a wide range of dissociation constants $\left(K_{\mathrm{i}}\right)$ against Def of $B$. subtilis possessed MIC values for $B$. subtilis which could be correlated with the $K_{\mathrm{i}}$ values of the inhibitors (Huntington et al., 2000). This is only possible if $\mathrm{YkrB}$ is inhibited as efficiently as Def by peptide thiols, since our data demonstrate that def alone is not essential for growth of B. subtilis and $y k r B$ also encodes a functional deformylase. Obviously, the class I and class II deformylases of B. subtilis possess similar enzymic properties in a cellular as well as in a cell-free system.

\section{B. subtilis probably contains more YkrB than Def}

When we tested the sensitivity of $B$. subtilis carrying deletions in either $\operatorname{def}$ or $y k r B$, we found that the $y k r B$ deletion mutant MHY101 was more sensitive to actinonin than the def-deletion strain MHD101. While the MIC values for MHY101 were $0 \cdot 3-0 \cdot 5 \mu \mathrm{g} \mathrm{ml}^{-1}$, the MIC values of MHD101 correspond to the MIC values for the wild-type strain $\left(1.9 \mu \mathrm{g} \mathrm{ml}^{-1}\right)$. When we compared the growth curves of mutants and wild-type strain with actinonin treatment, an increased sensitivity of the $y k r B$-deletion mutant MHY101 in comparison to the def-deletion strain MHD101 could also be demonstrated (compare strains MHY101+actinonin and MHD101+actinonin in Fig. 5b). Since Def and YkrB possess similar enzymic properties and are inhibited by actinonin with the same efficiency, the simplest and most probable explanation for the different sensitivity of deletion mutants to actinonin is that $B$. subtilis contains more $\mathrm{YkrB}$ proteins than Def proteins. Thus deletion of $y k r B$ makes B. subtilis more sensitive to actinonin than deletion of def.

Northern analyses support the idea that $y k r B$ is more highly expressed in B. subtilis than $\operatorname{def}$ (Fig. 3). We were able to detect a monocistronic transcript in B. subtilis wild-type and in the def-deletion strain MHD101, which disappeared in the $y k r B$-deletion strain MHY101. In contrast, we were not able to clearly identify def 
transcripts in B. subtilis wild-type and in the $y k r B$ deletion mutant using digoxigenin-labelled probes, although def-containing transcripts in a strain overexpressing def could be detected using the same probe.

Taking the results of the actinonin sensitivity tests and the Northern analyses together, we can conclude that YkrB is probably the predominant deformylase in $B$. subtilis, although final experiments on the protein level have to be performed to strengthen this conclusion.

\section{Actinonin resistance of organisms with two deformylases}

Besides B. subtilis, there are other organisms including important pathogens such as $S$. aureus which contain two deformylase genes. In $S$. aureus, one of the two def copies (the one which is associated with fmt in the chromosome) exhibits deviations in the catalytically important sequence motifs (Fig. 1) and has been identified to be inactive (Margolis et al., 2000). In $B$. subtilis, both Def-like proteins harbour conserved sequence motifs (Fig. 1) and are indeed functional. Several other pathogens, such as Pseudomonas aeruginosa, Streptococcus pneumoniae and Streptococcus pyogenes, could also possess two functional deformylases (Margolis et al., 2000; Giglione et al., 2000). Redundancy of essential functions in the bacterial cell can have serious implications for generation of resistance to drugs targeting the respective enzymes. Resistance can simply be achieved through a gene dosage effect or by mutations in which one copy of the gene encodes an enzyme resistant to the antibiotic while the other one continues to function normally. We therefore compared the actinonin-resistance frequency of $B$. subtilis strains carrying only one def-like gene (MHD101 and MHY101) to that of $B$. subtilis 168 . Remarkably, actinonin resistance arose in each strain at approximately the same frequency of $10^{-5}$. (The frequencies for each strain were determined twice.) One reason for this phenomenon could be that alterations in the fmt genes are the favoured resistance mechanisms even in organisms with two functional deformylases. The lack of formylation makes deformylation dispensable for the cell. This mode of resistance has been described in S. aureus, which harbours only one functional deformylase (Margolis et al., 2000). Sequence analyses of the relevant chromosomal loci in the resistant B. subtilis strains will be necessary to confirm the hypothesis.

\section{Conclusions}

From the evolutionary point of view, two classes of deformylases evolved which possess distant sequence similarity to each other, but which retain similarity in the essential sequence motifs (Fig. 1) and in 3-D structure (Dardel et al., 1998). Comparison of the two deformylases from B. subtilis illustrates that they possess remarkably similar enzymic properties and can be targeted by the antibiotic actinonin with the same efficiency. Actinonin indeed harbours antibacterial activity against a broad spectrum of bacteria which contain either class I or class II deformylases. B. subtilis is the first organism where expression and functionality of both def-like genes has been demonstrated. Although each of the two genes individually retains viability of $B$. subtilis, the gene product $\mathrm{YkrB}$ probably represents the predominant deformylase species in the organism. The presence of two deformylases in the cell does not necessarily increase the resistance frequency to antibiotics targeting peptide deformylation, such as actinonin. As in other organisms, resistance mechanisms not directly connected to the target also seem to be favoured in B. subtilis.

\section{ACKNOWLEDGEMENTS}

We thank E. Fischer and M. Oberborbeck for technical assistance and N. Brunner for help with many aspects of this work.

\section{REFERENCES}

Adams, J. M. (1968). On the release of the formyl group from nascent protein. J Mol Biol 33, 571-589.

Anagnostopoulos, C. \& Spizizen, J. (1961). Requirements for transformation in Bacillus subtilis. J Bacteriol 81, 741-746.

Belouski, E., Gui, L., Rudolph, F. B. \& Bennett, G. N. (1998). Complementation of an Escherichia coli polypeptide deformylase mutant with a gene from Clostridium acetobutylicum ATCC 824. Curr Microbiol 36, 248-249.

Bradford, M. M. (1976). A rapid and sensitive method for the quantitation of microgram quantities of protein utilizing the principle of protein-dye binding. Anal Biochem 72, 248-254.

Braun, H. P. \& Schmitz, U. K. (1993). Purification and sequencing of cytochrome $b$ from potato reveals methionine cleavage of a mitochondrially encoded protein. FEBS Lett 316, 128-132.

Chen, D. Z., Patel, D. V., Hackbarth, C. J. \& 9 other authors (2000). Actinonin, a naturally occurring antibacterial agent, is a potent deformylase inhibitor. Biochemistry 39, 1256-1262.

Dardel, F., Ragusa, S., Lazennec, C., Blanquet, S. \& Meinnel, T. (1998). Solution structure of nickel-peptide deformylase. J Mol Biol 280, 501-513.

Durand, D. J., Gordon Green, B., O'Connell, J. F. \& Grant, S. K. (1999). Peptide aldehyde inhibitors of bacterial peptide deformylases. Arch Biochem Biophys 367, 297-302.

Evans, V. J., Liyanage, H., Ravagnani, A., Young, M. \& Kashket, E. R. (1998). Truncation of peptide deformylase reduces the growth rate and stabilizes solvent production in Clostridium beijerinckii NCIMB 8052. Appl Environ Microbiol 64, 1780-1785.

Ferrari, F. A., Nguyen, A., Lang, D. \& Hoch, J. A. (1983). Construction and properties of an integrable plasmid for Bacillus subtilis. J Bacteriol 154, 1513-1515.

Giglione, C., Pierre, M. \& Meinnel, T. (2000). Peptide deformylase as a target for new generation, broad spectrum antimicrobial agents. Mol Microbiol 36, 1197-1205.

Guerout-Fleury, A. M., Frandsen, N. \& Stragier, P. (1996). Plasmids for ectopic integration in Bacillus subtilis. Gene 180, 57-61.

Harwood, C. R. \& Cutting, S. M. (1990). Molecular Biological Methods for Bacillus. Chichester: Wiley.

Huntington, K. M., Yi, T., Wei, Y. \& Pei, D. (2000). Synthesis and antibacterial activity of peptide deformylase inhibitors. Biochemistry 39, 4543-4551. 
Itaya, M., Kondo, K. \& Tanaka, T. (1989). A neomycin resistance gene cassette selectable in a single copy state in the Bacillus subtilis chromosome. Nucleic Acids Res 17, 4410.

Kim, L., Mogk, A. \& Schumann, W. (1996). A xylose-inducible Bacillus subtilis integration vector and its application. Gene 181, 71-76.

Kozak, M. (1983). Comparison of initiation of protein synthesis in procaryotes, eucaryotes, and organelles. Microbiol Rev 47, 1-45.

Leiting, B., Marsilio, F. \& O'Connell, J. F. (1998). Predictable deuteration of recombinant proteins expressed in Escherichia coli. Anal Biochem 265, 351-355.

Margolis, P. S., Hackbarth, C. J., Young, D. C., Wang, W., Chen, D., Yuan, Z., White, R. \& Trias, J. (2000). Peptide deformylase in Staphylococcus aureus: resistance to inhibition is mediated by mutations in the formyltransferase gene. Antimicrob Agents Chemother 44, 1825-1831.

Mazel, D., Pochet, S. \& Marliere, P. (1994). Genetic characterization of polypeptide deformylase, a distinctive enzyme of eubacterial translation. EMBO J 13, 914-923.

Mazel, D., Coic, E., Blanchard, S., Saurin, W. \& Marliere, P. (1997). A survey of polypeptide deformylase function throughout the eubacterial lineage. J Mol Biol 266, 939-949.

Meinnel, T. (2000). Peptide deformylase of eukaryotic protists: a target for new antiparasitic agents? Parasitol Today 16, 165-168.

Meinnel, T. \& Blanquet, S. (1993). Evidence that peptide deformylase and methionyl-tRNA(fMet) formyltransferase are encoded within the same operon in Escherichia coli. J Bacteriol 175, 7737-7740.
Meinnel, T. \& Blanquet, S. (1994). Characterization of the Thermus thermophilus locus encoding peptide deformylase and methionyl-tRNA(fMet) formyltransferase. J Bacteriol 176, 7387-7390.

Meinnel, T., Lazennec, C., Villoing, S. \& Blanquet, S. (1997). Structure-function relationships within the peptide deformylase family. Evidence for a conserved architecture of the active site involving three conserved motifs and a metal ion. J Mol Biol 267, 749-761.

Rygus, T. \& Hillen, W. (1992). Catabolite repression of the $x y l$ operon in Bacillus megaterium. J Bacteriol 174, 3049-3055.

Sambrook, J., Fritsch, E. F. \& Maniatis, T. (1989). Molecular Cloning: a Laboratory Manual, 2nd edn. Cold Spring Harbor, NY : Cold Spring Harbor Laboratory.

Shanklin, J., DeWitt, N. D. \& Flanagan, J. M. (1995). The stroma of higher plant plastids contain $\mathrm{ClpP}$ and $\mathrm{ClpC}$, functional homologs of Escherichia coli ClpP and ClpA : an archetypal two-component ATP-dependent protease. Plant Cell 7, 1713-1722.

Sherman, F., Stewart, J. W. \& Tsunasawa, S. (1985). Methionine or not methionine at the beginning of a protein. Bioessays 3, 27-31.

Solbiati, J., Chapman-Smith, A., Miller, J. L., Miller, C. G. \& Cronan, J. E., Jr (1999). Processing of the $\mathrm{N}$ termini of nascent polypeptide chains requires deformylation prior to methionine removal. J Mol Biol 290, 607-614.

Received 23 November 2000; revised 22 February 2001; accepted 28 February 2001. 